\title{
Micro-computed tomography evaluation of microleakage of Class II composite restorations: An in vitro study
}

\author{
Angelo Zavattini ${ }^{1}$, Manuele Mancini ${ }^{2}$, James Higginson ${ }^{3}$, Federico Foschi ${ }^{4}$, \\ Guido Pasquantonio ${ }^{2}$, Francesco Mangani $^{2}$
}

Correspondence: Dr. Angelo Zavattini

Email: zavattinia@cardiff.ac.uk

\author{
'Department of Restorative Dentistry, School of \\ Dentistry, Cardiff University, Cardiff, UK, \\ ${ }^{2}$ Department of Clinical Sciences and Translational \\ Medicine, University of Rome Tor Vergata, Rome RM, \\ Italy, \\ ${ }^{3}$ Department of Oral and Maxillofacial Surgery, \\ Institute of Head and Neck Studies and Education, \\ School of Cancer Sciences, University of Birmingham, \\ Edgbaston, Birmingham B15 2TT, UK, \\ ${ }^{4}$ Department of Conservative Dentistry, King's \\ College London Dental Institute, Guy's Hospital, \\ London SE1 9RT, UK
}

\section{ABSTRACT}

Objective: The aim of this study is to investigate the microleakage attained with three resin-based material used to restore deep Class II cavities. A null hypothesis was chosen: there is no difference in microleakage among the tested materials. Materials and Methods: A total of 30 Class II cavities were prepared in freshly extracted molars with the proximal mesial and distal margins located, respectively, $1.5 \mathrm{~mm}$ apically and $1.5 \mathrm{~mm}$ coronally to the cementum-enamel junction. Restorations were completed using a three-step enamel-dentin adhesive system "Etch and Rinse," margins were relocated using a micro-hybrid, preheated, or flowable composite and restorations were then completed using a conventional composite. All samples were coated with nail varnish with the exception of an area along the margins and apex was sealed using epoxide cement and then thermocycled ( 30 -s dwell time, $5^{\circ} \mathrm{C} / 55^{\circ} \mathrm{C}, 1000$ cycles). A $50 \%$ ammoniac $\mathrm{AgNO} 3$ solution was used as tracer according to Tay's protocol. The microleakage analysis was performed using a microtomography system Sky-scan 1072 (SKYSCAN, Kartuizersweg 3B 2550, Konitch, Belgium). Results: The mean microleakage of all the tested materials showed greater leakage in the cementum margins; flowable composite exhibit greater leakage among the groups. Significant differences $(P<5 \%)$ within groups in both enamel and dentin margins were present. None of the tested materials eliminated marginal microleakage. Preheated composite showed significantly lesser microleakage. Conclusion: Tested materials showed statistical differences in microleakage; thus, the null hypothesis has been rejected. Within the limitations of the present experimental procedure, it can be concluded that flowable resin composite should be avoided at the dentin/cementum margin.

Key words: Adhesion, Class II, deep margin relocation, direct restoration, micro-computed tomography CT, microleakage

\begin{tabular}{|l|l|}
\hline \multicolumn{3}{|c|}{ Access this article online } \\
\hline Quick Response Code: \\
\hline
\end{tabular}

This is an open access journal, and articles are distributed under the terms of the Creative Commons Attribution-NonCommercial-ShareAlike 4.0 License, which allows others to remix, tweak, and build upon the work non-commercially, as long as appropriate credit is given and the new creations are licensed under the identical terms.

For reprints contact: reprints@medknow.com

How to cite this article: Zavattini A, Mancini M, Higginson J, Foschi F, Pasquantonio G, Mangani F. Micro-computed tomography evaluation of microleakage of Class II composite restorations: An in vitro study. Eur J Dent 2018;12:369-74.

DOI: 10.4103/ejd.ejd_28_18 
Zavattini, et al.: An in vitro study to evaluate microleakage in II mesio-occlusal-distal Class II resin composite restorations using a micro-CT scan and a metal tracer

\section{INTRODUCTION}

Nowadays, the resin composites are the main dental material used as direct fillings. Their chemistry has evolved strikingly over the past years due to the use of different novel filler particles along with innovative low-shrinkage monomers. ${ }^{[1,2]}$ These are only some of the advances in this field. An old major drawback of the resin composite fillings was the excessive wear. However, some of the current materials can present enamel-like wear which decreases substantially the formation of gaps and stairs along the outer enamel-resin borders. ${ }^{[3]}$ This border is fundamental for the durability of the restorations since it has higher resistance against degradation. ${ }^{[4,5]}$ The resin-dentin interfaces are not as hydrolytically stable as the enamel margins so that the practitioners should limit to enamel the boundaries of the cavities. Nevertheless, in some cases, Class II cavities resulted from deep proximal caries below the cementum-enamel junction (CEJ) require restorations with gingival dentin margins. The dentin-bonded interfaces compromise the long-lasting durability of the fillings due to the faster degradation attained by hydrolysis of collagen which may be accelerated by enzymatic activity. ${ }^{[6,7]}$ In these cases, a suitable alternative would be, for instance, the indirect technique which would be less compromising than the direct filling as the former exposes less collagen. However, even the indirect restorative procedures may undergo marginal microleakage. The microleakage is related to the seepage of molecules, fluids, and bacteria within gaps between the cavity walls and the dental filling along the outer borders. ${ }^{[8]}$ Some outcomes of microleakage are tooth sensitivity, pulpal inflammation, and secondary caries. ${ }^{[9]}$ Several strategies have been proposed to reduce the microleakage; for instance, the use of ceramic inserts, ${ }^{[10]}$ the use of glass ionomer cement as a base, ${ }^{[11]}$ and the use of immediate dentin sealing or the so-called resin-coat technique. ${ }^{[12]}$ The latter relies on the use of a bonding agent and a flowable resin composite after the cavity preparations. The flowable composite may act as a stress-relieving more elastic liner and may provide better marginal integrity with less microleakage due to its low viscosity. ${ }^{[13]}$ Using such approach, the margins may be relocated upper to the enamel cavosurface border. Therefore, the final direct restoration could have only enamel surrounding borders. This relocation might be undertaken also with preheated composites which showed improved degree of conversion and less shrinkage stress. ${ }^{[14]}$ Nevertheless, there is little information on the use of preheated resin composites as a liner for direct restorations. Thus, the purpose of the present work is to investigate the microleakage attained after the use of flowable, preheated and micro-hybrid composites as a liner to relocate coronally gingival margins in the proximal boxes of the MOD cavities. The null hypothesis chosen was that there is no difference between the resin-based materials on the microleakage along the borders of direct restorations.

\section{MATERIALS AND METHODS}

\section{Specimen preparation}

Thirty selected molars, removed for periodontal reasons, were used in this study (gathered as approved by the Research Ethical Committee of the University of "Rome Tor Vergata"). All teeth were sound, completely formed, and free from pathology. Specimens were kept in distilled water for no $>1$ month at $4^{\circ} \mathrm{C}$ before being used. Mesio-occluso-distal preparations were completed, with the interproximal margins located, respectively, $1.5 \mathrm{~mm}$ apically (dentin/cementum) and $1.5 \mathrm{~mm}$ coronally (enamel) to the CEJ. Standard cavities were obtained with $4 \mathrm{~mm}$ in width and $2 \mathrm{~mm}$ in depth at the proximal boxes. All walls were prepared straight with rounded internal line angles and no retentive grooves. All II MOD cavities were completed using coarse diamond burs $(846 \mathrm{KR}$, Komet Italia srl, Milano) under copious water spray and finished with fine-grained burs of the same shape $(8846 \mathrm{KR}$, Komet Italia srl, Milano). The 30 specimens were randomly allocated to one of the three experimental groups, corresponding to the combination of restorative materials as described in Table 1.

\section{Sample preparation}

An adhesive system "Etch and Rinse" was used to treat dentin surfaces, according to the manufacturer's instructions, following groups of Table 1. With the exception of Group A (Control group), a layer

\begin{tabular}{|c|c|c|}
\hline Groups & Adhesive & $\begin{array}{l}\text { Relocation's } \\
\text { materials }\end{array}$ \\
\hline $\begin{array}{l}\text { Micro-hybrid composite } \\
\text { (controll group) }\end{array}$ & $\begin{array}{l}\text { Etch and } \\
\text { Rinse }\end{array}$ & $\begin{array}{l}\text { Premise Dentin A3 Kerr } \\
\text { BN. } 4396739\end{array}$ \\
\hline $\begin{array}{l}\text { Preheated } \\
\text { micro-hybrid composite }\end{array}$ & $\begin{array}{l}3 \text { steps } \\
\text { Optibond - FL }\end{array}$ & $\begin{array}{l}\text { Premise Dentin A3 Kerr } \\
\text { BN. } 4396739\end{array}$ \\
\hline Flowable & BN. 4190785 & $\begin{array}{l}\text { Premise flowable Kerr } \\
\text { BN. } 4264444\end{array}$ \\
\hline
\end{tabular}

Schematic representations of the restorative procedures used in the study. Specimens under evaluation ( $n=10$ samples per group). Groups divided based on the material used to relocate the margins 
of composite 1,0-1,5 mm thick was applied on all the gingival floor (mesial and distal), using, respectively, a flowable (Premise Flowable) or a preheated composite (Premise Dentin A3), to relocate the margins coronally to the CEJ. The resin composite was applied after placing an auto matrix (Dentsply-Caulk) and light-cured from the occlusal surface for $30 \mathrm{~s}$ with a power density of $1200 \mathrm{~mW} / \mathrm{cm}^{2}$ (Bluephase, Ivoclar-Vivadent, Schaan, Liechtestein). The restoration was then completed with 3-4 layers of the conventional composite using a horizontal placement technique of 1-1.5 mm composite thickness and light-cured for $30 \mathrm{~s}$. Build-ups were finished and polished using diamond burs $(40 \mu \mathrm{m})$ and discs of decreasing grain size (Optidisc, Kerr, Orange) as shown in Figure $1 a$ and $b$.

\section{Thermocycling procedures}

All specimens from each group were wrapped in gauze and placed in bag named with the corresponding group. Specimens were thermocycled in distilled water for 1000 cycles $\left(5-55^{\circ} \mathrm{C}\right)$ with dwell time of $30 \mathrm{~s}$ and draining time of $10 \mathrm{~s}$ between cycles.

\section{Dye penetration test}

With the exception of 1-mm thick area around the restoration margin the specimens where covered with two layers of nail varnish and the apex of each tooth was sealed with epoxide cement. A 50\% ammoniac AgNO3 solution was used as tracer and after 1 day of water storage at $37^{\circ} \mathrm{C}$, all the specimens were infiltrated as described by Tay et al. ${ }^{[15]}$

\section{Micro-ct analysis}

Microleakage analysis was performed using a microtomography system Sky-scan 1072
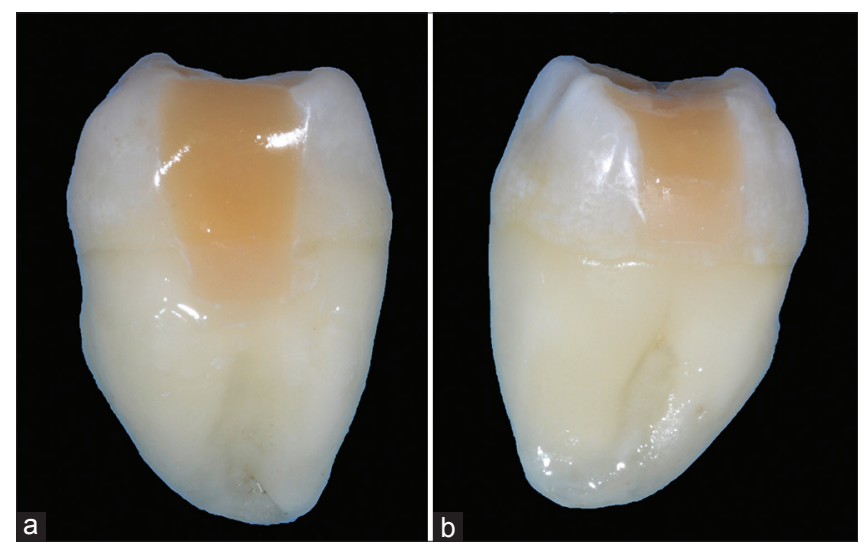

Figure 1: ( $a$ and $b)$ Specimens restored using a preheated composite to relocate the margins on dentin (a) and enamel (b). Restorations is completed with conventional composite
(SKYSCAN, Kartuizersweg 3B 2550, Konitch, Belgium). The settings of the machine were as follow: $100 \mathrm{kV}, 10 \mathrm{~W}$ and $98 \mu \mathrm{A}$, a standard aluminum filter and $\times 15$ magnification were applied. Final resolution was in the range of pixels $19.1 \mu \mathrm{m} \times 19.1 \mu \mathrm{m}$ and around 3-5 h were necessary to complete scan on each sample.

The data acquired were bi-dimensional images processed into cross-sectional images with a resolution of $19.1 \mu \mathrm{m} \times 19.1 \mu \mathrm{m}$ and a slice thickness of $13.0 \mu \mathrm{m}$.

The pattern of infiltration was digitally assessed with a dedicated system (TView SkyScan, bvba), which allowed observing of all micro scans and detecting the leakage of $\mathrm{AgNO} 3$ as shown in Figures 2a-c and 3. Three-dimensional 3D images were obtained by juxtaposition of 2D images of adjacent slices [Figure 4]. Since the beginning and the end of the procedure, microleakage could be observed in each scan and the infiltration was measured with the accuracy up to $0.001 \mathrm{~mm}$. The computed tomography analyzer (CTAan) (SkyScan, bvba) software was used for the determination volume of the AgNO3. A desktop X-ray microfocus CT scanner (SkyScan 1072, bvba, Aartselaar, Belgium) was used.

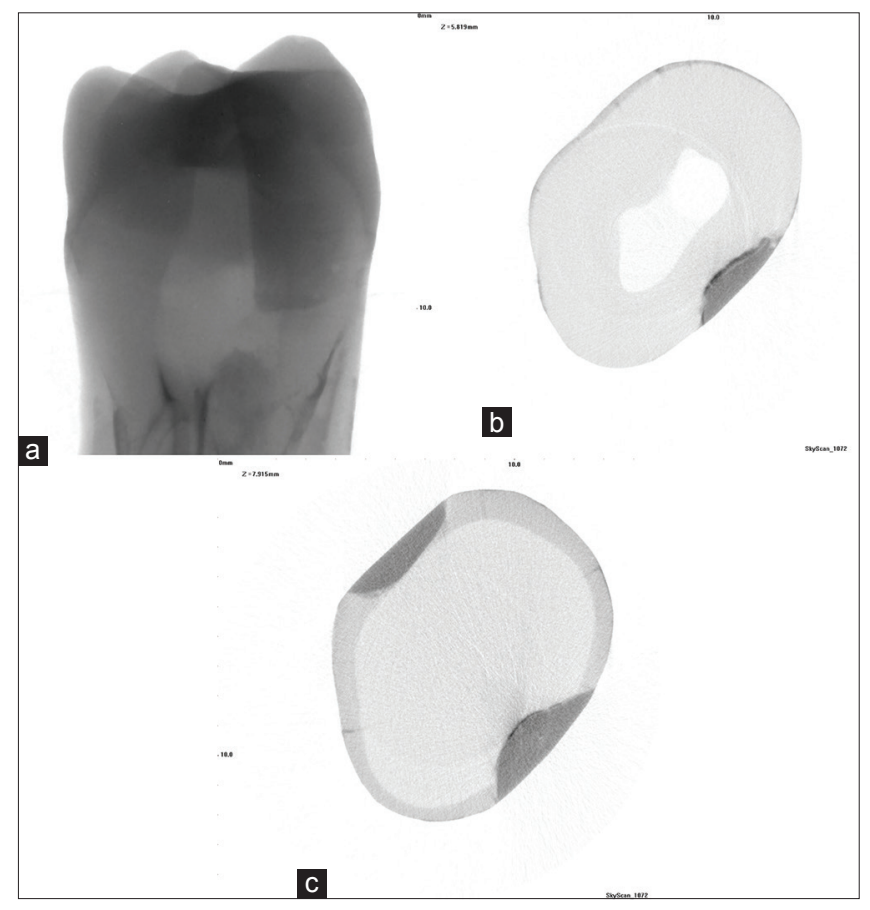

Figure 2: (a) X-ray projection image of the II MOD class of specimen C1 (Group C) obtained with micro-computed tomography scan. (b and c) Coronal micros-computed tomography scans of the same specimen showing presence of AgNO3 infiltration along the dentin margin. Note that enamel margin (c) does not present any infiltration in this case 
Zavattini, et al.: An in vitro study to evaluate microleakage in II mesio-occlusal-distal Class II resin composite restorations using a micro-CT scan and a metal tracer

\section{RESULTS}

The acquired data were evaluated on the basis of recorded volume from $\mathrm{AgNO} 3$ infiltration expressed in $\mathrm{mm}^{3}$ [Table 2]. The evaluation was conducted to assess microleakage patterns in both enamel and dentin margins. Statistical analysis was performed using $t$-test (two-tailed) to compare the differences in enamel and dentin/cementum margins, and one-way ANOVA was used to determine differences among groups. Microleakage's mean of all tested materials showed greater leakage in the cementum margins compared to enamel margins. There were statistically significant differences in microleakage between enamel and dentin margins [Table 3]. Descriptive statistical analysis depicts that flowable composite showed maximum microleakage with a mean of $0.74 \mathrm{~mm}^{3}$ at the cementum margin [Table 4 and Figure 5]. ANOVA test showed the presence of significant

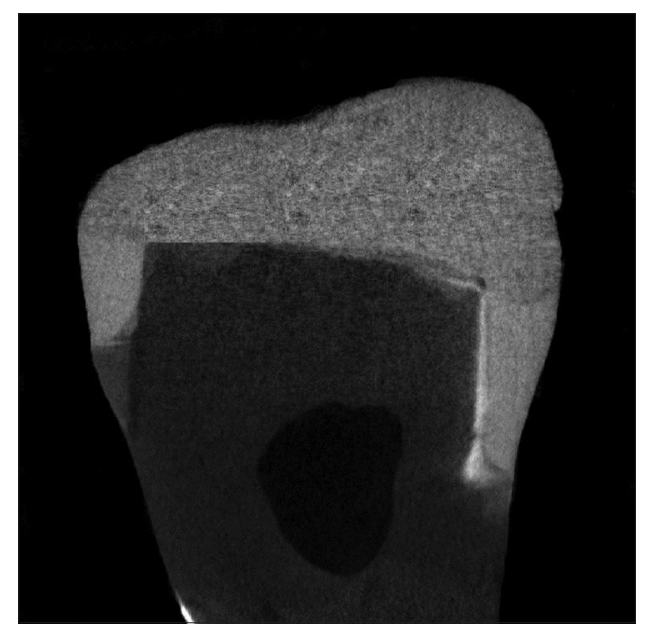

Figure 3: Axial view of $\mathrm{C} 1$ specimen, maximum intensity projection image, which is similar to a two-dimensional radiograph of the Volume of Interest where is possible to appreciate the presence of AgNO3 alongside the dentin margin differences $(P<5 \%)$ within groups in both enamel and dentin margins.

\section{DISCUSSION}

Microleakage is the undetectable passage of bacteria, fluids, molecules, and ions at the interface between the cavity walls and the restorative material bonded to. It can be used as a measure by which clinicians can evaluate the performance ability of dental materials within the oral environment. ${ }^{[16]}$ The most important aspect of microleakage is the direct link with the formation of secondary marginal caries. Although a lot of methods and strategies have been used to reduce this phenomenon, microleakage is still present and affect the longevity of the restorations. ${ }^{[2]}$ When facing a MOD II cavity with deep margins in dentin and/or cementum, with resin composite, microleakage can frequent occur if a good dentin/bonding interface is not achieved. ${ }^{[17]}$ Restoration of a deep Class II cavities has always been a topic of debate. Adhesion

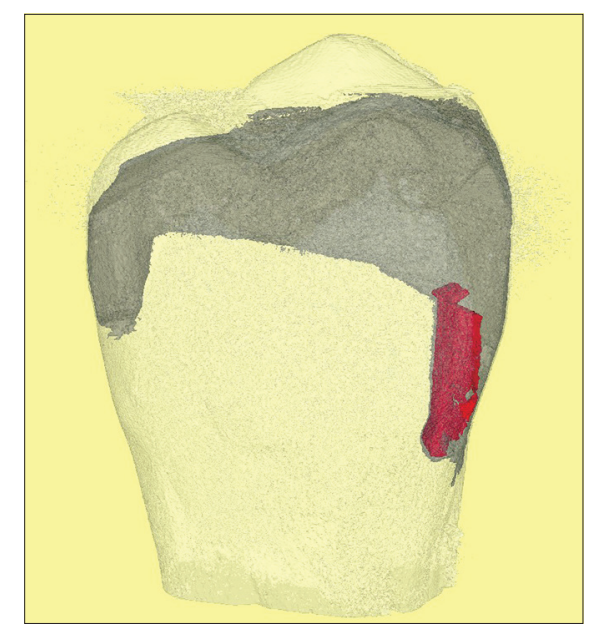

Figure 4: Three-dimensional volume rendering of specimen $\mathrm{C} 1$ post infiltration; in red volume of $\mathrm{AgNO} 3$

Table 2: Results of microleakage distribution in each group

\begin{tabular}{|c|c|c|c|c|c|}
\hline \multicolumn{2}{|c|}{$\begin{array}{c}\text { Group A } \\
\text { Micro-hybrid composite }\end{array}$} & \multicolumn{2}{|c|}{$\begin{array}{c}\text { Group B } \\
\text { Preheated composite }\end{array}$} & \multicolumn{2}{|c|}{$\begin{array}{c}\text { Group C } \\
\text { Flowable composite }\end{array}$} \\
\hline Enamel $\left(\mathrm{mm}^{3}\right)$ & Dentin $\left(\mathrm{mm}^{3}\right)$ & Enamel $\left(\mathrm{mm}^{3}\right)$ & Dentin $\left(\mathrm{mm}^{3}\right)$ & Enamel $\left(\mathrm{mm}^{3}\right)$ & Dentin $\left(\mathrm{mm}^{3}\right)$ \\
\hline 0.017 & 0.123 & 0.015 & 0.023 & 0.019 & 1.877 \\
\hline 0.013 & 0.119 & 0.013 & 0.19 & 0.022 & 1.168 \\
\hline 0.012 & 0.056 & 0.012 & 0.16 & 0.023 & 1.158 \\
\hline 0.010 & 0.045 & 0.00 & 0.15 & 0.018 & 1.221 \\
\hline 0.010 & 0.040 & 0.00 & 0.02 & 0.018 & 1.10 \\
\hline 0.011 & 0.043 & 0.00 & 0.02 & 0.015 & 0.53 \\
\hline 0.008 & 0.032 & 0.00 & 0.00 & 0.013 & 0.45 \\
\hline 0.00 & 0.013 & 0.00 & 0.00 & 0.012 & 0.023 \\
\hline 0.00 & 0.00 & 0.00 & 0.00 & 0.010 & 0.021 \\
\hline 0.00 & 0.00 & 0.00 & 0.00 & 0.010 & 0.00 \\
\hline
\end{tabular}


to dentin/cementum is still a challenge because the nature of the substrate so the quality of the margins of a bonded restoration is questionable. ${ }^{[18]}$ In 1998, Dietschi and Spreafico proposed a conservative approach to such challenge, the deep margin elevation technique. The procedure consisted in the placement of composite underneath indirect bonding restoration to relocate coronally the proximal margins. ${ }^{[19]}$ The DME concept can also be used in direct restoration as reported by Magne in synergy with the immediate dentine sealing technique. ${ }^{[20]}$ There has been controversy on which material can be successfully used to relocate the deep margin of II classes. Several authors reported that the use of flowable material at the deep margin of Class II could show a good sealing ability and marginal adaptation. ${ }^{[14,21]}$ Other authors revealed

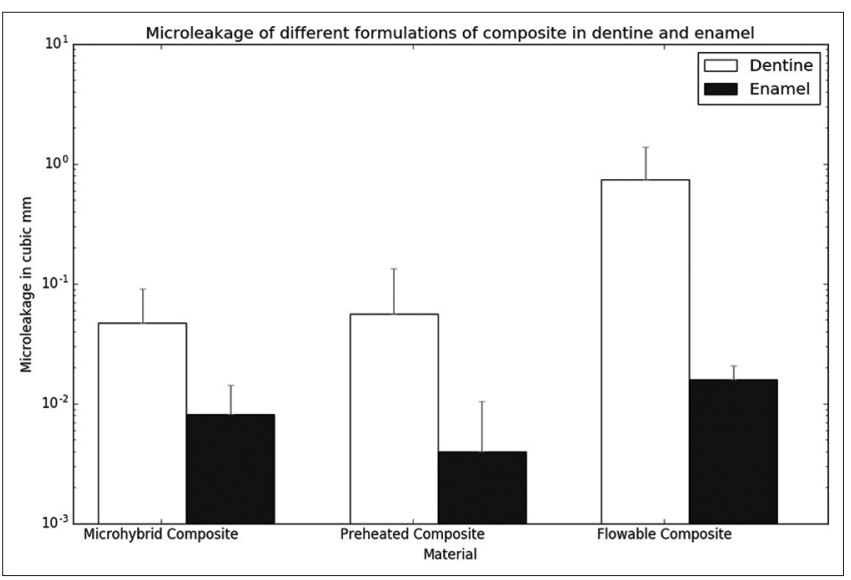

Figure 5: Graphic log-bar chart, microleakage of different formulations of composite in dentine and enamel, measured in $\mathrm{mm}^{3}$

\begin{tabular}{lcc} 
Table 3: $\boldsymbol{t}$-test results & & \\
\hline Groups & $\boldsymbol{P}$ & Significance \\
\hline Flowable & 0.001 & $\mathrm{~S}$ \\
Micro-hybrid & 0.011 & $\mathrm{~S}$ \\
Preheated micro-hybrid & 0.047 & $\mathrm{~S}$ \\
\hline
\end{tabular}

Two-tailed $t$-test. Comparison between enamel and dentin/cementum margins. S: Significant that flowable materials used at the dentin margin showed high microleakage score when compared to nonflowable materials. The preheated composite is also advocated for reducing microleakage at the dentin/cementum margins. ${ }^{[22,23]}$ The study evaluated the microleakage of deep Class II cavities to determine the bonding capacity of the given resin-based materials in both enamel as well as cement area. Thermocycling was done completely according to the ideal timing. The apical extent of the Class II was intentionally placed into root surface on one side because in this area, microleakage is known to be a clinical concern. Previous microleakage studies have found significant differences in the amount of microleakage at enamel versus cementum margins in relation to the material used with a huge variety of results. ${ }^{[24]}$ This big diversity of results may be due to different methods used to detect the microleakage, techniques, and protocols used to restore an II deep class. In this study, microleakage was detected using a CT-scan and a metal tracer. As reported by Neves et al., this technique has shown good sensitivity to evaluate the pattern of silver nitrate infiltration at the resin-tooth interface. ${ }^{[25]}$ In all tested materials of this study, a degree of microleakage was observed. However, the preheated composite showed less leakage compared to the others in cementum margins and was possible to reject the tested null hypothesis. The flowable material showed high infiltration in both margins, enamel, and dentin, and was possible to record from the CT-scan a maximum volume of $1.87 \mathrm{~mm}^{3}$. The results of this study showed that the majority of the microleakage occur at the cementum/dentin margin, and confirm that an optimal adhesion to dentin/cementum is still a challenge. For instance, the results of this research indicate that the use of a flowable material should be avoided in the dentin/cementum margin. Further studies testing these materials in vivo are recommended to determine the potential clinical effect.

\begin{tabular}{|c|c|c|c|c|c|c|}
\hline \multirow{2}{*}{$\begin{array}{l}\text { Group } \\
\text { Margin location }\end{array}$} & \multicolumn{2}{|c|}{ A - Micro-hybrid composite } & \multicolumn{2}{|c|}{ B - preheated composite } & \multicolumn{2}{|c|}{ C -Flowable composite } \\
\hline & Enamel & Dentin & Enamel & Dentin & Enamel & Dentin \\
\hline Count & 10 & 10 & 10 & 10 & 10 & 10 \\
\hline Mean & 0.008 & 0.047 & 0.004 & 0.056 & 0.016 & 0.744 \\
\hline SD & 0.006 & 0.043 & 0.006 & 0.078 & 0.005 & 0.635 \\
\hline Minimum & 0 & 0 & 0 & 0 & 0.01 & 0 \\
\hline $25 \%$ & 0.002 & 0.018 & 0 & 0 & 0.012 & 0.130 \\
\hline $50 \%$ & 0.01 & 0.041 & 0 & 0.02 & 0.016 & 0.815 \\
\hline $75 \%$ & 0.012 & 0.053 & 0.009 & 0.118 & 0.019 & 1.149 \\
\hline Maximum & 0.017 & 0.123 & 0.015 & 0.19 & 0.023 & 1.877 \\
\hline
\end{tabular}




\section{CONCLUSION}

Within the limitations of this in vitro study, it can be concluded that a flowable composite should be avoided at the dentin/cementum margin. Therefore, in clinical situation, if the cavity margin is placed below the CEJ, it is advisable to line the cavity with preheated composite-based material to reduce the incidence of microleakage.

\section{Financial support and sponsorship \\ Nil.}

\section{Conflicts of interest}

There are no conflicts of interest.

\section{REFERENCES}

1. Magne P, Dietschi D, Holz J. Esthetic restorations for posterior teeth: Practical and clinical considerations. Int J Periodontics Restorative Dent 1996;16:104-19.

2. Deliperi S. Functional and aesthetic guidelines for stress-reduced direct posterior composite restorations. Oper Dent 2012;37:425-31.

3. Liebenberg WH. Assuring restorative integrity in extensive posterior resin composite restorations: Pushing the envelope. Quintessence Int 2000;31:153-64.

4. Deliperi S, Bardwell DN. Clinical evaluation of direct cuspal coverage with posterior composite resin restorations. J Esthet Restor Dent 2006;18:256-65.

5. Kenyon BJ, Frederickson D, Hagge MS. Gingival seal of deep class II direct and indirect composite restorations. Am J Dent 2007;20:3-6.

6. Rocca GT, Gregor L, Sandoval MJ, Krejci I, Dietschi D. In vitro evaluation of marginal and internal adaptation after occlusal stressing of indirect class II composite restorations with different resinous bases and interface treatments. "Post-fatigue adaptation of indirect composite restorations". Clin Oral Investig 2012;16:1385-93.

7. Kidd EA. Microleakage: A review. J Dent 1976;4:199-206.

8. Araujo Fde O, Vieira LC, Monteiro Junior S. Influence of resin composite shade and location of the gingival margin on the microleakage of posterior restorations. Oper Dent 2006;31:556-61.

9. Cardoso MV, de Almeida Neves A, Mine A, Coutinho E, Van Landuyt K, De Munck J, et al. Current aspects on bonding effectiveness and stability in adhesive dentistry. Aust Dent J 2011;56 Suppl 1:31-44.

10. Rodrigues Junior SA, Pin LF, Machado G, Della Bona A, Demarco FF Influence of different restorative techniques on marginal seal of class II composite restorations. J Appl Oral Sci 2010;18:37-43.

11. Fabianelli A, Pollington S, Davidson C, Cagidiaco MC, Goracci C. Scientific relevance of micro - Leakage studies. Mod Dent Med 2007;9:64-74.

12. Karagenç B, Gençoglu N, Ersoy M, Cansever G, Külekçi G. A comparison of four different microleakage tests for assessment of leakage of root canal fillings. Oral Surg Oral Med Oral Pathol Oral Radiol Endod 2006;102:110-3.

13. Leevailoj C, Cochran MA, Matis BA, Moore BK, Platt JA. Microleakage of posterior packable resin composites with and without flowable liners. Oper Dent 2001;26:302-7.

14. Sadeghi M, Lynch CD. The effect of flowable materials on the microleakage of class II composite restorations that extend apical to the cemento-enamel junction. Oper Dent 2009;34:306-11.

15. Tay FR, Pashley DH, Garcia-Godoy F, Yiu CK. Single-step, self-etch adhesives behave as permeable membranes after polymerization. Part II. silver tracer penetration evidence. Am J Dent 2004;17:315-22.

16. Hamouda I, Abd Elkader H, Badawi MF. Microleakage of nanofilled composite resin restorative material. J Biomater Nanobiotechnol 2011;2:329-34.

17. Relhan N, Ponnappa KC, Relhan A, Jain A, Gupta P. An in-vitro comparison of micro leakage between two posterior composites restored with different layering techniques using two different LED modes. J Clin Diagn Res 2015;9:ZC78-81.

18. Ferrari M, Davidson CL. Sealing performance of Scotchbond multi-purpose-Z100 in class II restorations. Am J Dent 1996;9:145-9.

19. Dietschi D, Spreafico R. Current clinical concepts for adhesive cementation of tooth-colored posterior restorations. Pract Periodontics Aesthet Dent 1998;10:47-54.

20. Magne P. Deep margin elevation technique: A paradigm shift. Am J Esthet Dent 2012;2:86-96.

21. Fabianelli A, Sgarra A, Goracci C, Cantoro A, Pollington S, Ferrari M, et al. Microleakage in class II restorations: Open vs. closed centripetal build-up technique. Oper Dent 2010;35:308-13.

22. Sensi LG, Marson FC, Monteiro S Jr., Baratieri LN, Caldeira de Andrada MA. Flowable composites as "filled adhesives": A microleakage study. J Contemp Dent Pract 2004;5:32-41.

23. Wagner WC, Aksu MN, Neme AM, Linger JB, Pink FE, Walker S, et al. Effect of pre-heating resin composite on restoration microleakage. Oper Dent 2008;33:72-8.

24. Castelnuovo J, Tjan AH, Liu P. Microleakage of multi-step and simplified-step bonding systems. Am J Dent 1996;9:245-8.

25. Neves AA, Jaecques S, Van Ende A, Cardoso MV, Coutinho E, Lührs AK, et al. 3D-microleakage assessment of adhesive interfaces: Exploratory findings by $\mu$ CT. Dent Mater 2014;30:799-807. 